\title{
Focus issue on plant immunity: from model systems to crop species
}

\author{
Benjamin Schwessinger ${ }^{1,2 *}$, Rebecca Bart ${ }^{3}$, Ksenia V. Krasileva ${ }^{4,5}$ and Gitta Coaker ${ }^{1 *}$ \\ ' Department of Plant Pathology, University of California, Davis, CA, USA, ${ }^{2}$ Lawrence Berkeley National Laboratory, Joint \\ BioEnergy Institute and Physical Biosciences Division, Berkeley, CA, USA, ${ }^{3}$ Donald Danforth Plant Science Center, St. Louis, \\ MO, USA, ${ }^{4}$ The Genome Analysis Centre, Norwich Research Park, Norwich, UK, ${ }^{5}$ The Sainsbury Laboratory, Norwich \\ Research Park, Norwich, UK
}

Keywords: crops, agricultural, innate immunity, plant pathology, translational research, immune signaling

\section{OPEN ACCESS}

Edited by:

Giulia De Lorenzo,

University of Rome La Sapienza, Italy

Reviewed by:

Vincenzo Lionetti,

Sapienza "Università di Roma," Italy

*Correspondence:

Benjamin Schwessinger and Gitta Coaker,

bschwessinger@ucdavis.edu; glcoaker@ucdavis.edu

Specialty section:

This article was submitted to Plant-Microbe Interaction, a section of the journal Frontiers in Plant Science

Received: 17 February 2015 Accepted: 11 March 2015 Published: 26 March 2015

Citation:

Schwessinger B, Bart R, Krasileva KV and Coaker G (2015) Focus issue on plant immunity: from model systems to crop species.

Front. Plant Sci. 6:195. doi: 10.3389/fpls.2015.00195
One of the largest challenges of our time is to enhance agricultural production to feed a growing population in the midst of a changing climate. According to estimates, the global population will increase from 7 to 9 billion people by 2050 requiring a 60\% increase in food in order to meet demand (Alexandratos and Bruinsma, 2012). Only the combination of reduction of food waste together with an increase in food productivity will enable us to meet this daunting challenge (Godfray et al., 2010). Advancements in agricultural practices, technology, food transport, and crop yields on marginal lands will be required to address this looming food production challenge. Crop losses due to plant disease significantly impact agriculture, with $\sim 15 \%$ of global crop production lost due to preharvest plant disease (Pinstrup-Andersen, 2001; Oerke, 2006). Studies of model plants, such as Arabidopsis, have significantly enhanced our understanding of plant innate immune perception and signaling. For example, the identification of classical plant resistant genes in Arabidopsis and other model dicots facilitated the successful cloning of multiple wheat rust resistant genes (Ellis et al., 2014; Wulff and Moscou, 2014). With advancements in genome sequencing and analyses, we are now at a stage to exploit the basic knowledge gained in plant model species at a full genome scale in crops (Piquerez et al., 2014).

This Research Topic encompasses a collection of reviews, opinions, perspectives, as well as primary research articles investigating the interaction between crop plants and a variety of pathogens including fungi, bacteria, viruses and aphids (Ellis et al., 2014; Huet, 2014; Jaouannet et al., 2014; Nicaise, 2014; Stergiopoulos and Gordon, 2014; Wiesel et al., 2014). Immune receptors with extracellular domains can recognize pathogen proteins or conserved microbial signatures in the apoplast. Robinson and Bostock (2015) highlight the role of oomycete branched $\beta$-1,3-glucans and eicosapolyenoic acids for eliciting plant immune responses in a variety of plants. In light of recent research, these "elicitors" are likely conserved microbial signatures and can be reclassified as microbe associated molecular patterns (MAMPs) (Robinson and Bostock, 2015). Several articles reveal commonalities as well as differences in pathogen perception and signaling across diverse plant species (Barrios Perez and Brown, 2014; De Vleesschauwer et al., 2014; Figueiredo et al., 2014; Piquerez et al., 2014), highlighting the need for investigating innate immunity in wide array of plants with a focus on crop species. The same sets of hormones are critical for defense signaling in vascular plants. However, as illustrated by De Vleesschauwer et al. (2014) in their comparison of Arabidopsis and rice, the molecular mechanisms and the effect on the cross-talk between different hormones can vary significantly. Studies focusing on the molecular factors that define and limit pathogen host range as well as the ability to transfer non-host resistance (NHR) across plant species will significantly enhance scientist's ability to develop novel disease control strategies (Bettgenhaeuser et al., 2014; Stam et al., 2014). Rust fungi are a group of broadly distributed plant pathogens. However, distinct rust pathogens can exhibit very broad host range (Phakopsora pachyrhizi), narrow host range (Puccinia triticina) or a continuum between the two (Bettgenhaeuser et al., 2014). According to Stam et al. (2014), current evidence supports the hypothesis 
that in distantly related plant species NHR is mostly driven by the pathogens inability to suppress pattern recognition receptor mediated immunity at the plasma membrane. However, in closely related plant species NHR is mostly caused by the recognition of effector molecules by intracellular immune receptors containing nucleotide binding site and c-terminal leucine rich repeats (NLRs) (Stam et al., 2014). The interactions between different microorganisms, pathogenic and nonpathogenic, should also be considered when investigating plant defense and NHR, because interactions between plant colonizing organisms can impact disease development and outcome (Hale et al., 2014; Stergiopoulos and Gordon, 2014). When analyzing plant microbiomes, it will be important to complement survey studies with hypothesis-driven research, such as those outlined by Hale et al. (2014).

Parasitic plants, viruses as well as insects significantly impact agricultural production. Aphids cause significant crop losses by acting as a vector for plant viruses as well as causing damage due to feeding (Jaouannet et al., 2014). Jaouannet et al. (2014) highlight the importance of aphid-plant interactions as well as the role of classical plant immune receptors and signaling networks in recognizing these insect pathogens. Similarly, immunity against parasitic plants of the genus Cuscuta is hypothesized to employ the same classes of immune receptors yet knowledge of the molecular mechanisms involved during the infection process and the ensuing immune response are still sparse (Kaiser et al., 2015). In addition to these classic plant defense pathways, antiviral immunity involves several distinct RNA interference pathways that limit pathogen replication and spread (Nicaise, 2014).

We have entered an exciting era of research on plantpathogen-microbe interactions. Large-scale genome sequencing of both plant and pathogen populations is now feasible and can help formulate multiple testable hypotheses. The "Integrated Decoy Hypothesis" posed by Dodds and colleagues was developed from a combination of wet lab experiments coupled with genome analyses to identify genetically linked NLR pairs, where

\section{References}

Alexandratos, N., Bruinsma, J. (2012). World Agriculture towards 2030/2050: The 2012 Revision. ESA Working Paper No. 12-03. Rome; FAO.

Barrios Perez, I., and Brown, P. J. (2014). The ROLE of ROS Signaling in Cross-Tolerance: from model to crop. Front. Plant Sci. 5:754. doi: 10.3389/fpls.2014.00754

Bettgenhaeuser, J., Gilbert, B., Ayliffe, M., and Moscou, M. J. (2014). Nonhost resistance to rust pathogens - a continuation of continua. Front. Plant Sci. 5:664. doi: $10.3389 /$ fpls.2014.00664

Cesari, S., Bernoux, M., Moncuquet, P., Kroj, T., and Dodds, P. N. (2014). A novel conserved mechanism for plant NLR protein pairs: the 'integrated decoy' hypothesis. Front. Plant Sci. 5:606. doi: 10.3389/fpls.2014. 00606

De Vleesschauwer, D., Höfte, M., and Xu, J. (2014). Making sense of hormonemediated defense networking: from rice to Arabidopsis. Front. Plant Sci. 5:611. doi: 10.3389/fpls.2014.00611

Ellis, J. G., Lagudah, E., Spielmeyer, W., and Dodds, P. (2014). The past, present and future of breeding rust resistant wheat. Front. Plant Sci. 5:641. doi: $10.3389 /$ fpls.2014.00641 one receptor has an additional "sensing" domain targeted by effectors (Cesari et al., 2014). This hypothesis can now be directly tested to determine if "sensor" NLRs are decoys for pathogen effectors or bona fide virulence targets using existing near isogenic lines (Wu et al., 2015). Conserved secretion signals have enabled the identification of thousands of candidate effectors in oomycete and bacterial pathogens. Pathogen genomes can also be mined to identify core effectors. These core effectors can be subsequently used to screen germplasms known to harbor resistance(s) to identify the recognized effector and cognate NLR gene. This knowledge of the molecular identities will enable the deployment of cultivars recognizing conserved pathogen effectors and monitoring their allelic variation in the field (Huet, 2014; Vasudevan et al., 2014; Wulff and Moscou, 2014). To date screens identifying $N L R$ /effector pairs are still a major bottleneck in plant microbe research, because they are time consuming and labor intensive. The development of accurate, high throughput phenotyping platforms will significantly impact our ability to identify promising phenotypes and facilitate hypothesis testing (Mutka and Bart, 2015). We hope that this special focus issue on crop immunity will serve as an important reference for the interaction between plants, pathogens and their biotic environment.

\section{Acknowledgments}

GC is supported by grants from the NIH (RO1GM092772) and USDA (2015-67013-23082). BS is supported by a Human Frontier Science Program (HFSP) long-term postdoctoral fellowship (LT000674/2012). RB is supported by the Bill and Melinda Gates Foundation (OPP1093529) and Cotton Inc. (15-749). KVK is supported by the strategic funding from Biotechnology and Biological Sciences Research Council (BBSRC) and the Gatsby Charitable Foundation. We apologize to all contributors of this Research Topic, whose work could not be discussed in greater detail due to space limitations.

Figueiredo, A., Monteiro, F., and Sebastiana, M. (2014). Subtilisin-like proteases in plant pathogen recognition and immune priming: a perspective. Front. Plant Sci. 5:739. doi: 10.3389/fpls.2014.00739

Godfray, H. C. J., Beddington, J. R., Crute, I. R., Haddad, L., Lawrence, D., Muir, J. F., et al. (2010). Food security: the challenge of feeding 9 Billion People. Science 327, 812-818. doi: 10.1126/science. 1185383

Hale, I. L., Broders, K., and Iriarte, G. (2014). A Vavilovian approach to discovering crop-associated microbes with potential to enhance plant immunity. Front. Plant Sci. 5:492. doi: 10.3389/fpls.2014.00492.

Huet, G. (2014). Breeding for resistances to Ralstonia solanacearum. Front. Plant Sci. 5:715. doi: 10.3389/fpls.2014.00715

Jaouannet, M., Rodriguez, P. A., Thorpe, P., Lenoir, C. A., Macleod, R., EscuderoMartinez, C., et al. (2014). Plant immunity in plant-aphid interactions. Front. Plant Sci. 5:663. doi: 10.3389/fpls.2014.00663

Kaiser, B., Fürst, U. B., Vogg, G., and Albert, M. (2015). Parasitic plants of the genus Cuscuta and their interaction with susceptible and resistant host plants. Front. Plant Sci 6:45. doi: 10.3389/fpls.2015.00045

Mutka, A., and Bart, R. (2015). Image-based phenotyping of plant disease symptoms. Front. Plant Sci. 5:734. doi: 10.3389/fpls.2014.00734

Nicaise, V. (2014). Crop immunity against viruses: outcomes and future challenges. Front. Plant Sci. 5:660. doi: 10.3389/fpls.2014.00660. 
Oerke, E.-C. (2006). Crop losses to pests. J. Agric. Sci. 144, 31-43. doi: $10.1017 /$ S0021859605005708

Pinstrup-Andersen, P. (2001). The future world food situation and the role of plant diseases. Plant Health Instructor. Available online at: https://www.apsnet.org/ publications/apsnetfeatures/Pages/WorldFoodSituation.aspx

Piquerez, S. J. M., Harvey, S. E., Beynon, J. L., and Ntoukakis, V. (2014). Improving crop disease resistance: lessons from research on Arabidopsis and tomato. Front. Plant Sci.5:671. doi: 10.3389/fpls.2014.00671

Robinson, S. M., and Bostock, R. M. (2015). $\beta$-Glucans and eicosapolyenoic acids as MAMPs in plant-oomycete interactions: past and present. Front. Plant Sci. 5:797. doi: 10.3389/fpls.2014.00797

Stam, R., Mantelin, S., Mclellan, H., and Thilliez, G. (2014). The role of effectors in nonhost resistance to filamentous plant pathogens. Front. Plant Sci. 5:582. doi: 10.3389/fpls.2014.00582

Stergiopoulos, I., and Gordon, T. R. (2014). Cryptic fungal infections: the hidden agenda of plant pathogens. Front. Plant Sci. 5:506. doi: 10.3389/fpls.2014. 00506

Vasudevan, K., Vera Cruz, C. M., Gruissem, W., and Bhullar, N. K. (2014). Large scale germplasm screening for identification of novel rice blast resistance sources. Front. Plant Sci. 5:505. doi: 10.3389/fpls.2014. 00505
Wiesel, L., Newton, A. C., Elliott, I., Booty, D., Gilroy, E. M., Birch, P. R. J., et al. (2014). Molecular effects of resistance elicitors from biological origin and their potential for crop protection. Front. Plant Sci. 5:655. doi: 10.3389/fpls.2014.00655

Wu, C.-H., Krasileva, K. V., Banfield, M. J., Terauchi, R., and Kamoun, S. (2015) The "Sensor domains" of plant NLR proteins: more than decoys? Front. Plant Sci. 6:134. doi: 10.3389/fpls.2015.00134

Wulff, B. B. H., and Moscou, M. J. (2014). Strategies for transferring resistance into wheat: from wide crosses to GM cassettes. Front. Plant Sci. 5:692. doi: $10.3389 /$ fpls.2014.00692

Conflict of Interest Statement: The authors declare that the research was conducted in the absence of any commercial or financial relationships that could be construed as a potential conflict of interest.

Copyright (C) 2015 Schwessinger, Bart, Krasileva and Coaker. This is an open-access article distributed under the terms of the Creative Commons Attribution License (CC $B Y)$. The use, distribution or reproduction in other forums is permitted, provided the original author(s) or licensor are credited and that the original publication in this journal is cited, in accordance with accepted academic practice. No use, distribution or reproduction is permitted which does not comply with these terms. 